\title{
Feed Intake, Milk Yield, and Metabolic Parameters Prior to Left Displaced Abomasum in Dairy Cows
}

\author{
S. C. L. Van Winden, R. Jorritsma, K. E. Müller, and J. P. T. M. Noordhuizen \\ Department of Farm Animal Health, Faculty of Veterinary Medicine, \\ Utrecht University, Yalelaan 7, 3584 CL, Utrecht, The Netherlands
}

\begin{abstract}
As left-displaced abomasum (LDA) often occurs in cows with high contents of fat in the liver (fatty liver), a postpartum fatty liver-inducing regimen was applied to 16 cows. The main interest of the study was whether there were productive or metabolic changes in cows prior to LDA. Therefore, feed intake and milk production were monitored and blood samples were collected from the cows. The LDA occurred in 4 out of 16 dairy cows that were included in the feeding regimen. Compared to cows not developing LDA, LDA-cows had a significantly lower feed intake, $6.5 \mathrm{~kg} / \mathrm{d}$ less, and milk production, $8 \mathrm{~kg} / \mathrm{d}$ less, prior to clinical diagnosis of LDA. In the 10-d period preceding clinical diagnosis of LDA, blood concentrations of calcium, glucose, and insulin were significantly lower, whereas blood concentrations of nonesterified fatty acids and beta-hydroxybutyrate, as well as aspartate aminotransferase activities were significantly elevated compared to cows not developing LDA. These preclinical changes may play an important role in the pathogenesis of LDA. It is not certain, however, whether there is a causal association between these parameters and LDA.
\end{abstract}

(Key words: left-displaced abomasum, dairy cow, fatty liver)

Abbreviation key: LDA = left-displaced abomasum, NEB = negative energy balance, $\mathbf{T A G}=$ triacylglycerol .

\section{INTRODUCTION}

Left-displaced abomasum (LDA) is a disorder that occurs mainly in high producing postpartum dairy cows (Geishauser, 1995). The economic consequences of LDA are becoming more important as the incidence rate has been increasing to $5 \%$ of postpartum dairy cows (Geishauser et al., 2000). Normally, the abomasum contains fluid and is positioned in the ventral part of the abdo-

Received June 28, 2002.

Accepted August 15, 2002.

Corresponding author: S. C. L. Van Winden; e-mail:svwinden@ schothorst.nl. men. In postpartum cows the abomasum may shift to the left without causing clinical signs (Van Winden et al., 2002b). The LDA can be clinically detected if gas is present in the abomasum resulting in a tympanic, resonant, high-toned ping (Breukink and Kroneman, 1963). It is possible that the clinically present LDA resolves spontaneously; this LDA is in the veterinary field described as a floater. In this paper the persisting clinical LDA that needs veterinary intervention is referred to as LDA.

The early postpartum period is considered to be the major risk period, because hypocalcemia, metritis, negative energy balance (NEB), as well as nutritional factors, play a central role in the pathogenesis of LDA (Shaver, 1997). Dairy cows experience a NEB because the drain of energy for milk production exceeds the energy uptake from the ingested feedstuffs (Herdt, 2000). Metabolic characteristics of this NEB are hypoglycemia, hyperglycemia, ketonemia, high NEFA blood concentrations, and increased accumulation of triacylglycerol (TAG) in the liver (Herdt, 2000). The proportion of TAG in the liver can exceed $150 \mathrm{mg} / \mathrm{g}$ liver tissue. Fatty liver in cattle has been shown to be associated with an increased incidence of metabolic disorders (Reid and Roberts, 1982; Rukkwamsuk, 1999; Heuer, 2000). Metabolic disorders, directly and indirectly associated with NEB, are hypoglycemia, hyperglycemia, and ketonemia (Holtenius and Holtenius, 1996; Herdt, 2000). In addition, prolonged toxemia resulting from bacterial infections can be present in cows with fatty liver as a result of insufficient clearance: the normal functioning of the liver, i.e., eliminating toxins, is decreased (Hill et al., 1985; Ohtsuka et al., 2001). Various metabolic aberrations and the NEB as such have been reported to be associated with the development of displacement of the abomasum (Muylle et al., 1990; Geishauser, 1995). For example, Heuer (2000) reported that 53\% of the LDA cases are related to the effects of NEB. Geishauser et al. (2000) reported that BHBA and aspartate aminotransferase (ASAT) activity in the blood, both parameters associated with NEB of postpartum cows, may be used to predict the development of LDA. However, since the sensitivity and specificity of predicting a subsequent LDA in the second week after 
Table 1. Composition of the total mixed ration (TMR, DM $=455 \mathrm{~g} /$ $\mathrm{kg}$, containing $6.42 \mathrm{MJ} \mathrm{NE}_{\mathrm{L}} / \mathrm{kg} \mathrm{DM}$ ) fed throughout the experiment.

\begin{tabular}{lc}
\hline Component & $\begin{array}{l}\text { TMR composition } \\
(\%, \text { DM basis })\end{array}$ \\
\hline Maize silage $^{1}$ & 52 \\
Rape seed meal $^{2}$ & 8 \\
Soybean meal $^{3}$ & 17 \\
Sugar beet pulp $^{4}$ & 21 \\
Minerals & 2 \\
\hline
\end{tabular}

${ }^{1}$ Characteristics of maize silage per kg DM: 213 g crude fiber, 73 $\mathrm{g}$ crude protein, $179 \mathrm{~g}$ crude ash, $335 \mathrm{~g}$ starch, $422 \mathrm{~g}$ NDF, $228 \mathrm{~g}$ $\mathrm{ADF}, 25 \mathrm{~g}$ ADL.

${ }^{2} \mathrm{DM}=877 \mathrm{~g} / \mathrm{kg}$.

${ }^{3} \mathrm{DM}=870 \mathrm{~g} / \mathrm{kg}$.

${ }^{4}$ Extracted, DM $=905 \mathrm{~g} / \mathrm{kg}$.

calving are low $(\mathrm{BHBA}>1.0 \mathrm{mmol} / \mathrm{l}$ : sensitivity $=0.64$ and specificity $=0.69$, ASAT $>100 \mathrm{U} / \mathrm{l}$ : sensitivity $=0.79$ and specificity $=0.69$ ), not all cows undergoing NEB will develop LDA (Geishauser et al., 2000).

As LDA often occurs in cows with fatty liver, a postpartum fatty liver-inducing regimen was applied to 16 cows. The main interest of the present experiment was to detect changes in cows prior to LDA. To this end, feed intake and milk production was monitored and blood samples were collected from the cows. Of the 16 dairy cows included in the study, four cows developed LDA. Cows with LDA were matched, based on parity and fatty contents of the liver tissue, with cows not developing LDA. A retrospective analysis was performed on metabolic parameters in order to detect differences between the two groups.

\section{MATERIALS AND METHODS}

\section{Animals and Nutritional Regimen}

The study took place under the supervision and with approval of the Ethical Review Committee of Animal Experimentation of the Faculty of Veterinary Medicine, Utrecht University in the Netherlands. In the experiment starting at six weeks before calving, sixteen Holstein-Friesian cows of parity three to seven were included. The cows were kept in a tied-housing system with sawdust bedding. The animals had free access to water throughout the experiment. All animals received a TMR twice per day at 1000 and $2200 \mathrm{~h}$ during the entire experimental period; the composition of the TMR is given in Table 1 and contained 6.42 $\mathrm{MJ} \mathrm{NE}_{\mathrm{L}} / \mathrm{kg} \mathrm{DM}$. Because DA occurrence is associated with NEB (Heuer, 2000), a fatty liver-inducing feeding regimen was used (Van der Top et al., 1995). To this end, six cows were individually fed during the dry period according to the Dutch recommendations for energy requirements (Centraal Veevoeder Bureau, 1998); they received each 53
$\mathrm{MJ} \mathrm{NE}_{\mathrm{I}}$ /day to prevent over-conditioning (control group). After parturition, the cows were fed TMR for ad libitum consumption. The same TMR ad libitum in the dry period was fed to ten other cows. In order to predispose to fatty liver, these cows were fasted for eight hours after calving and thereafter they received each $22 \mathrm{~kg}$ TMR (10 kg DM), being 64.2 $\mathrm{MJ} \mathrm{NE}_{\mathrm{L}} /$ day. Starting from the sixth day of lactation, all cows received TMR for ad libitum consumption. Feed intake and milk production were recorded daily. Dry matter content was analyzed of the ration fed, as well as the leftovers. By means of scales, BW was measured each week. The cows were weighed at the beginning of the experiment $(730 \pm 24 \mathrm{~kg})$ and prior to calving $(775 \pm 24$ $\mathrm{kg})($ mean $\pm \mathrm{SEM})$.

Cows that showed sudden loss of appetite or a decreased milk production during the experimental period were clinically examined. Based on a tympanic, resonant, high-toned ping at the left abdominal wall, LDA was clinically diagnosed, and was confirmed by right flank laparotomy. After correcting the position of the abomasum the omentum major was fixated in the wound during closure of the abdomen (Trent, 1990).

\section{Sampling Procedure and Laboratory Analyses}

As we expected to detect the largest variation in blood parameters during the first three weeks, and less variation later in lactation, blood was collected from the jugular vein daily at 0700 and $1000 \mathrm{~h}$ during the first $22 \mathrm{~d}$ postpartum. Subsequently, blood was collected on d 24, 26,28 , and 31 of lactation. Additionally, blood was collected into appropriate tubes at 1200,2200 , and 2400 $\mathrm{h}$ on days 1 to $7,9,11,12,15$, and 21 after calving. The values of multiple samples that were collected on one day were averaged. Percutaneous liver biopsy samples were taken in the 11th intercostal space during the second week of lactation (Van der Top et al., 1995). Immediately after sampling, connective tissue and blood clots were disposed of and the samples were weighed and stored at $-20^{\circ} \mathrm{C}$. After thawing the samples, the amount TAG was determined, expressed as $\mathrm{mg} / \mathrm{g}$ wet weight of liver tissue, using a commercial test kit (kit number 337-A; Sigma Chemical Co., St. Louis, MO). Cows were categorized as moderate fatty liver cows (TAG between 50 and $100 \mathrm{mg} / \mathrm{g}$ liver tissue), severe fatty liver cows (TAG between 100 and $200 \mathrm{mg} / \mathrm{g}$ liver tissue), and extreme fatty liver cows (TAG higher than $200 \mathrm{mg} / \mathrm{g}$ liver tissue) (Gaal et al., 1983).

In all blood samples, glucose and beta-hydroxybutyrate (BHBA) concentrations were determined. In the samples of the first $21 \mathrm{~d}$ postpartum NEFA and insulin concentrations were determined. On d 3, 7, 9, 13, 15, and 17 postpartum gamma-glutamyl transpeptidase 
Table 2. Daily feed intake, milk production and blood values in the 10-d period before development of LDA, the values of the matched control cows (average \pm SEM) and the 95\% confidence interval (C.I.) of the reference value.

\begin{tabular}{lrcc}
\hline Variable & $\begin{array}{l}\text { LDA-cows } \\
(\mathrm{n}=4)\end{array}$ & $\begin{array}{l}\text { Control cows } \\
(\mathrm{n}=8)\end{array}$ & $\begin{array}{l}\text { Reference value } \\
(95 \% \text { C.I. })\end{array}$ \\
\hline Feed intake, kg/d of DM & $8.64 \pm 0.73$ & $15.27 \pm 0.68$ & $\ldots$ \\
Milk production, kg & $23.36 \pm 6.05$ & $31.59 \pm 7.64$ & $\ldots$ \\
NEFA, mmol/l & $1.23 \pm 0.11$ & $0.79 \pm 0.05$ & $0-0.8$ \\
Glucose, mmol/l & $2.46 \pm 0.22$ & $2.84 \pm 0.05$ & $2.5-4.0$ \\
Insulin, $\mu \mathrm{IU} / \mathrm{ml}$ & $1.12 \pm 0.20$ & $3.73 \pm 0.21$ & $0-5$ \\
BHBA, mmol/l & $3.45 \pm 0.39$ & $0.99 \pm 0.09$ & $0-1.2$ \\
GGT, U/ & $45.38 \pm 8.02$ & $26.13 \pm 1.62$ & $0-27$ \\
ASAT, U/ & $130.00 \pm 20.97$ & $75.13 \pm 5.67$ & $10-70$ \\
Cortisol, nmol/l & $2.27 \pm 0.71$ & $4.18 \pm 1.31$ & $15-19$ \\
Calcium, $\mathrm{mmol} / \mathrm{l}$ & $2.56 \pm 0.10$ & $2.74 \pm 0.06$ & $2.3-3.2$ \\
\hline
\end{tabular}

(GGT) activity, aspartate amino transferase (ASAT) activity, cortisol concentrations, and calcium concentrations were determined. These parameters were analyzed using standard test kits on a Beckman CX automatic analyzer.

Additionally, cortisol concentrations were determined on d 19 and 21 after calving. Cortisol and insulin concentrations were determined by radioimmunoassay (Coat-a-Count, Diagnostic Products Corp., Los Angeles).

\section{Statistical Analysis}

A cow that developed LDA was matched with two other healthy cows that did not develop LDA. Matching was based on parity, the level of fatty infiltration of the liver and the day of lactation.

The day of clinical diagnosis of LDA is defined as d 0 . Days prior to LDA were set from $d-1$ to $d-10$. The variables were analyzed with Linear Mixed Effects method, which takes dependency of the data into account and therefore is suitable to statistically analyze repeated measurements (S-PLUS 2000, MathSoft Inc., Cambridge, United Kingdom). This method uses maximum likelihood techniques for estimating the fit of the model. The identity of the cow was used as random effect. The following formula for the fixed effects was used: $\mathrm{Y}=$ FL-severity + Day PP + PRIOR $\times$ LDA, where $\mathrm{Y}=$ feed intake, milk production and values of blood analyses; FL-severity = category of fatty liver, ordinal: moderate, severe, and extreme; Day PP = number of days postpartum, as a polynomial of the third order; PRIOR = day prior to LDA, between -10 and -1 , as polynomial of the third order; LDA = occurrence of LDA, binomial; and PRIOR $\times \mathrm{LDA}=$ interaction term to analyze whether the trend over time differed between the LDA cows and control cows. By putting day postpartum and severity of fatty infiltration of the liver in the beginning of the fixed effects formula, the term PRIOR and
DA, as well as the interaction of both are adjusted for the moment after calving and the severity of fatty liver. To determine whether the day postpartum, as well as the day prior to LDA should be linear, or a polynomial of the second, third or fourth order, a likelihood ratio test was performed in order to test whether the model did significantly improve compared to the less complex model. This resulted both for the day postpartum as well as day prior to LDA in a polynomial of the third order. Significance of the difference between LDA-cows and controls prior to DA, concerning feed intake, milk production, and values of blood analyses, were analyzed in separate models. For obtaining the point estimates of LDA, the formula had been run again without interaction term. The former formula was used to determine differences between LDA-cows and their matched controls, concerning the 10-d period prior to DA. In order to evaluate significant differences on one specific day, the analysis was performed with day prior to LDA as a factor. When only one value was present on that day, either in the LDA or the control group, significance could not be analyzed, since then there is no variation. Autocorrelation structures were tested and selected based on LR-test. The normality of the residuals and the random effects in the final model were visually checked with Q-Q plots.

\section{RESULTS}

Out of 16 cows, four developed LDA on d 4, 11, 21, and 29 after calving. Of the DA-cows, three had a severe fat infiltration of the liver (119, 187 and $200 \mathrm{mg} / \mathrm{g}$ liver tissue), while in one DA-cow the fatty infiltration of the liver was extreme ( $307 \mathrm{mg} / \mathrm{g}$ liver tissue). Out of 16 cows, 14 from both experimental groups revealed liver fat contents higher than $50 \mathrm{mg} / \mathrm{g}$ liver tissue in the second week postpartum. Of these cows two had extreme fatty liver, severe fatty liver occurred in seven cows, and a moderate fatty infiltration of the liver oc- 
Table 3. Levels of significance in the difference of the variables tested between LDA- and matched control cows. The size of effect of LDA is calculated without interaction term. Figures 1 to 6 should also be used for interpreting the size of effect and direction of the difference between cows that develop LDA and their matched control cows.

\begin{tabular}{|c|c|c|c|c|c|c|}
\hline \multirow{2}{*}{$\begin{array}{l}\text { Dependent } \\
\text { variable }\end{array}$} & \multirow{2}{*}{$\begin{array}{l}\text { Severity } \\
\text { FL }^{1}\end{array}$} & \multirow{2}{*}{$\begin{array}{l}\text { Day PP }{ }^{2} \\
(\text { poly, } 3)^{3}\end{array}$} & \multirow{2}{*}{$\begin{array}{l}\text { Prior }^{4} \\
(\text { poly, 3) }\end{array}$} & \multicolumn{2}{|c|}{ LDA } & \multirow{2}{*}{$\begin{array}{l}\text { Interaction } \\
\text { prior } \times \text { LDA }\end{array}$} \\
\hline & & & & $P$-value & Effect & \\
\hline DM intake, kg & $P=0.029$ & $P=0.019$ & N.S. ${ }^{5}$ & $P=0.077$ & -9.5 & $P<0.001$ \\
\hline Milk production, $\mathrm{kg} / \mathrm{d}$ & $P=0.094$ & $P=0.005$ & $P=0.009$ & $P=0.046$ & -6.4 & $P<0.001$ \\
\hline $\mathrm{NEFA}, \mathrm{mmol} / \mathrm{l}$ & $P=0.048$ & $P=0.092$ & $P=0.059$ & $P=0.088$ & 0.36 & $P=0.003$ \\
\hline Glucose, $\mathrm{mmol} / \mathrm{l}$ & $P=0.089$ & $P=0.019$ & N.S. & $P=0.070$ & -0.37 & N.S. \\
\hline Insulin, $\mu \mathrm{IU} / \mathrm{ml}$ & $P=0.045$ & $P<0.001$ & $P=0.023$ & $P<0.001$ & -2.7 & N.S. \\
\hline BHBA, mmol/l & $P=0.002$ & $P<0.001$ & N.S. & $P<0.001$ & 2.2 & $P<0.001$ \\
\hline GGT, U/l & N.S. & N.S. & N.S. & N.S. & & N.S. \\
\hline ASAT, U/l & N.S. & $P=0.044$ & N.S. & $P=0.025$ & 52.2 & $P=0.085$ \\
\hline Cortisol, nmol/l & N.S. & N.S. & N.S. & N.S. & & N.S. \\
\hline Calcium, mmol/l & N.S. & N.S. & N.S. & $P=0.046$ & -0.26 & N.S. \\
\hline
\end{tabular}

${ }^{1} \mathrm{FL}=$ fatty infiltration of the liver.

${ }^{2}$ Day $\mathrm{PP}=$ day postpartum.

${ }^{3}$ poly, $3=$ as polynomial of the third order.

${ }^{4}$ Prior $=$ day prior to left-displaced abomasum (LDA).

${ }^{5}$ N.S. $=$ not significant at a $10 \%$ level (Type I error).

curred in five out of 14 cows. Maximum TAG contents in the liver was $307 \mathrm{mg} / \mathrm{g}$ tissue in the second week postpartum. The LDA-cows originated from the fatty liver induced group $(n=3)$ as well as the control diet group $(n=1)$. From the matched controls, nine came from the fatty liver induced group, and one from the group that had received the control diet.

Average daily feed intake, milk production and blood values in the 10-d period before development of LDA, as well as the values of the matched control cows are given in Table 2. Not adjusted for the day after calving, the concentrations of NEFA, BHBA, GGT and ASAT are higher in cows developing LDA compared with the matched control cows. Table 3 shows significant differences between LDA- and control cows for the variables tested in the linear mixed effects model. Adjusted for the day postpartum and the severity of fatty liver, and leaving out the interaction term (Prior $\times$ LDA), we found that feed intake $(-9.5 \mathrm{~kg} / \mathrm{d})$, milk production $(-6.4 \mathrm{~kg} /$ $\mathrm{d}$ ), calcium-, glucose- and insulin concentrations (respectively $-0.26 \mathrm{mmol} / \mathrm{l},-0.37 \mathrm{mmol} / \mathrm{l}$, and $-2.7 \mu \mathrm{IU} / \mathrm{ml}$ ) were significantly lower in cows that developed LDA. Nonesterified fatty acids $(0.36 \mathrm{mmol} / \mathrm{l})$, BHBA $(2.2$ $\mathrm{mmol} / \mathrm{l}$ ) and ASAT (52.2 U/l) levels were elevated in those cows. These differences can also be detected when looking at Figures 1 to 6 . These figures show, besides the difference contributed by LDA, also the trends over time: milk production, feed intake, BHBA, NEFA, insulin and ASAT in DA-cows and their control cows within the 10-d period before LDA diagnosis are presented. When comparing the parameters on individual days, BHBA concentrations were elevated, whereas the insulin concentrations were lowered in nearly the complete 10-d period in LDA-cows compared to their matched control cows (Figures 3 and 5). At d 4 prior to LDA detection, the DM intake was significantly lower in LDA-cows, which was, with respect to milk production, also the case at three days prior to LDA (Figure 1 and 2). NEFA was significantly elevated on one day before LDA occurred (Figure 4).

\section{DISCUSSION}

Retrospective analysis of results of a feeding trial revealed differences in parameters between animals that developed a clinically persistent LDA and animals

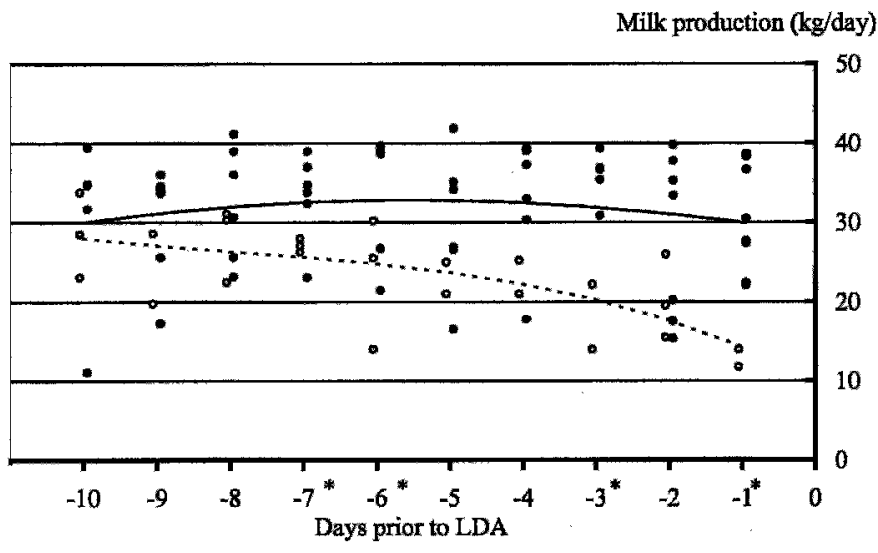

Figure 1. Milk production (kg/day) in LDA-cows prior to LDA $(\bigcirc,--)$ and their matched controls $(-,-)$. The line represents the polynomial regression line of the third order. Day 0 is the moment of LDA-development. *: significant difference $(P<0.10)$ between LDAand control cows at that day. 
DMI (kg/cow/day)

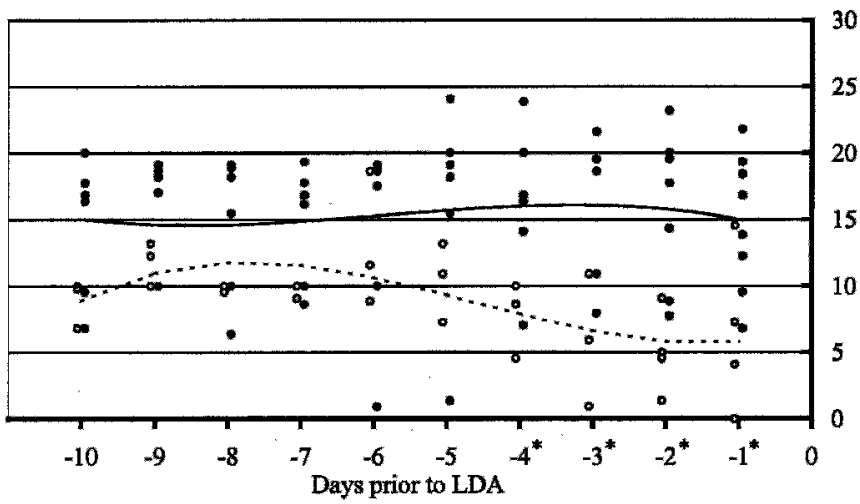

Figure 2. Feed intake (dry matter, DMI, kg/cow/day) in LDA-cows prior to LDA $(\mathrm{O},--)$ and their matched controls $(-$,$) . The line$ represents the polynomial regression line of the third order. Day 0 is the moment of LDA-development. *: significant difference $(P<$ 0.10 ) between LDA- and control cows at that day.

that did not. Cows that would develop displacement of the abomasum in general had lower feed intake, lower milk production, decreased blood calcium levels, elevated blood ketone body and NEFA concentrations, and high activity of ASAT compared to the matched animals. These findings are in accordance with previous reports concerning differences in the preclinical stage of LDA (Detillieux et al., 1997; Geishauser et al., 1998; Geishauser et al., 2000; Østergaard and Gröhn, 2000).

In the present study, two different phases in the 10$\mathrm{d}$ period can be identified based on the parameters that were evaluated. First, the period between ten and five days prior to LDA, and secondly the phase from four days before LDA until the day of DA. The latter period

BHBA (mmol/)

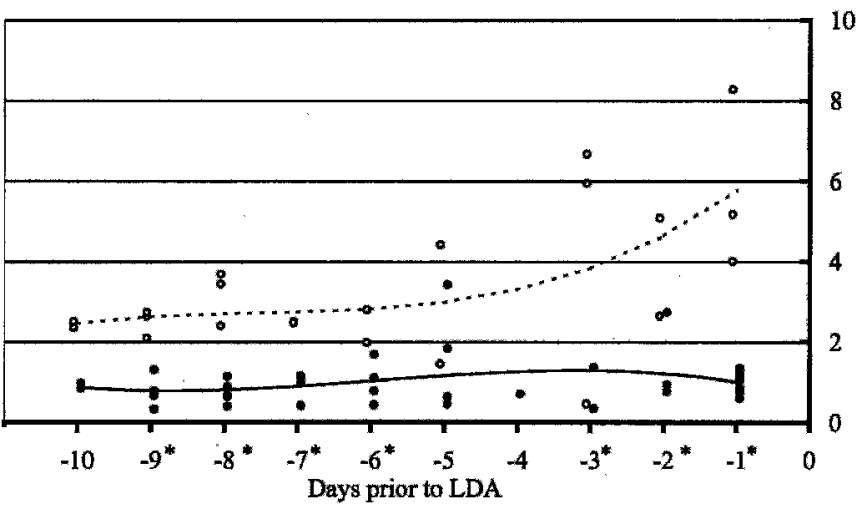

Figure 3. Beta-hydroxybutyrate (BHBA, mmol/l) concentration in blood of LDA-cows prior to LDA $(\mathrm{O},--)$ and their matched controls $(\bullet,-)$. The line represents the polynomial regression line of the third order. Day 0 is the moment of LDA-development. *: significant difference $(P<0.10)$ between LDA- and control cows at that day.

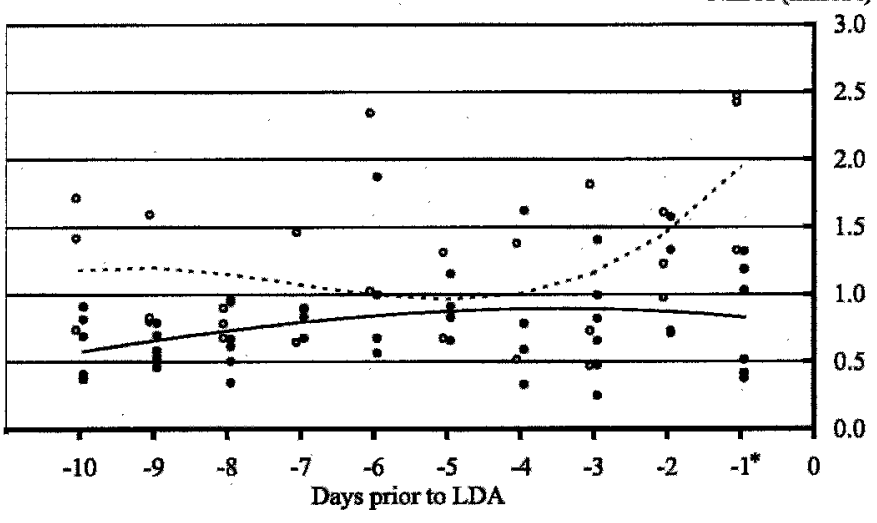

Figure 4. Nonesterified fatty acid concentration (NEFA, mmol/l) in blood of LDA-cows prior to LDA $(O,--)$ and their matched controls $(\boldsymbol{0},-)$. The line represents the polynomial regression line of the third order. Day 0 is the moment of LDA-development. *: significant difference $(P<0.10)$ between LDA- and control cows at that day.

can be interpreted in two ways. First, the abomasum can be sub-clinically dislocated several days before clinical diagnosis and the preclinical changes in the parameters are due to alterations of the position of the abomasum. The other interpretation is that changes in these last 4 days prior to LDA are putative (co-)initiators for DA, which is also mentioned in literature (Østergaard and Gröhn, 2000).

Reduced feed intake prior to LDA in fatty liver cows is the key element in the observed changes in parameters. A result of reduced feed intake is poor rumen fill. The poorly filled rumen enables the abomasum to shift to the left and finally the abomasum dislocates clinically (Dirksen, 1962; Van Winden et al., 2002b). As a conse-

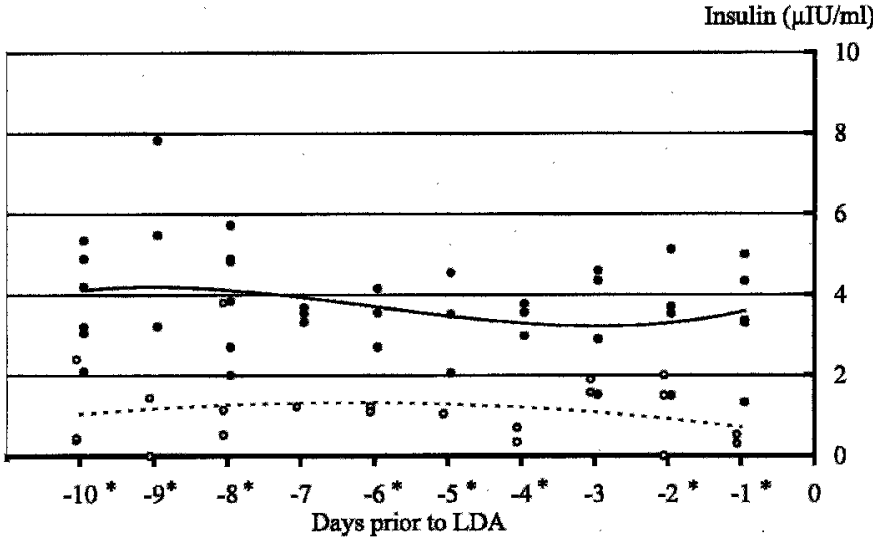

Figure 5. Insulin concentrations $(\mu \mathrm{IU} / \mathrm{ml})$ in blood of LDA-cows prior to LDA $(O,--)$ and their matched controls $(\bullet,-)$. The line represents the polynomial regression line of the third order. Day 0 is the moment of LDA-development. *: significant difference $(P<$ 0.10 ) between LDA- and control cows at that day. 


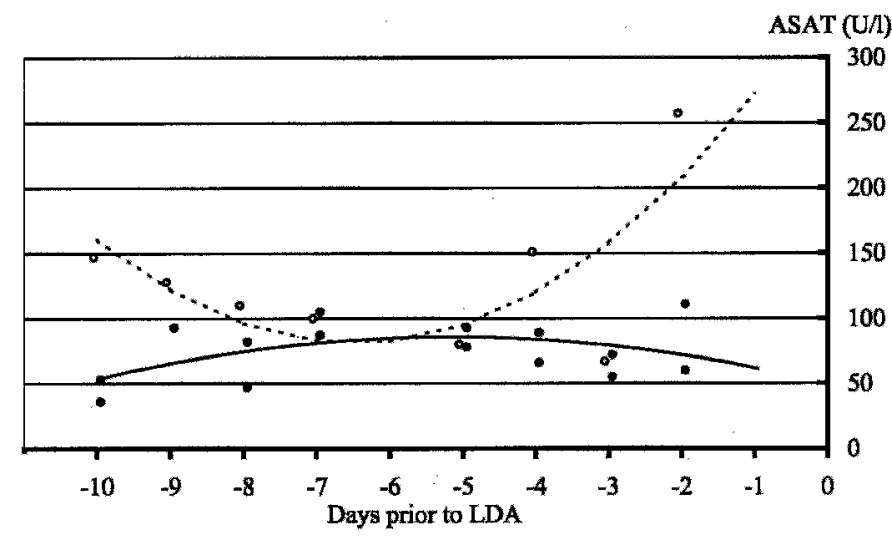

Figure 6. Aspartate amino transferase (ASAT, U/l) activity in blood of LDA-cows prior to LDA $(\bigcirc,--)$ and their matched controls $(\mathbf{O},-)$. The line represents the polynomial regression line of the third order. Day 0 is the moment of LDA-development.

quence of reduced feed intake blood concentrations of calcium and glucose decrease, followed by decreased blood insulin concentrations (Herdt, 2000; Østergaard and Gröhn, 2000). Another effect of low glucose levels in ruminants is ketone body production, leading to a rise of blood BHBA concentrations (Herdt, 2000). In addition a rise of ASAT activity in the blood has been assumed to be a result from protein mobilization from muscles in order to deliver glycogenic amino acids as glucose precursors (Herdt, 2000).

Abomasal emptying and digestive flow are positively correlated with the amount of feed intake and the degree of rumen fill (Gregory et al., 1985; Feng et al., 1993). Motility of the abomasum depends, besides on feed intake, on the tonicity of the vagal nerve, which in turn depends on afferent information of the autonomic system. A part of the autonomic system information is the concentration of glucose and insulin in the blood, as high concentrations of glucose and insulin increased the vagal tonicity, which in turn increased motility and gastric acid secretion under experimental conditions (Ash, 1961; Kovacs et al., 1995; Lam et al., 1997).

Besides the abomasal position in the abdomen and motility of the abomasum, at least a third reason for LDA development is necessary: gas production (Dirksen, 1962). A possible pathway for abomasal gas production is prolongation of fermentation in the abomasum (Van Winden et al., 2002a). They report an increase of abomasal $\mathrm{pH}$ in postpartum cows, in which passage of VFA, produced in the rumen but not absorbed in the rumen or omasum, into the abomasum could have a $\mathrm{pH}$ increasing role. The increase in $\mathrm{pH}$ enables the rumen bacterial flora to continue fermentation in the abomasum. As mentioned above, there is a stimulating effect of insulin on gastric acid production. Puscas et al. (2001) described a decreased acid production due to decreased calcium blood concentrations. This effect is caused by a vagal mechanism and by a direct effect on parietal cells; calcium is a second messenger for the increase in activity of carbonic anhydrase. In cows that developed clinical DA, decreased values of calcium were detected prior to LDA (Geishauser et al., 1998). Together with low values of insulin this might have led reduced acid secretion in the abomasum, resulting in increased gas production.

\section{CONCLUSIONS}

In cows that develop displacement of the abomasum, fatty liver is an important risk factor. In this experiment not all fatty liver cows developed clinical DA, but there were marked differences in variables between cows with fatty liver that did or did not develop clinical LDA. Cows that developed displacement of the abomasum in general had lower feed intake, lower milk production, decreased blood calcium levels, elevated blood ketone body and NEFA concentrations, and high activity of ASAT compared to the matched animals. These preclinical changes may play an important role in the pathogenesis of LDA. Whether there is a causal association between these parameters and LDA, however, is not certain.

\section{REFERENCES}

Ash, R. W. 1961. Stimuli influencing the secretion of acid by the abomasum of sheep. J. Physiol. (Lond.) 157:185-207.

Breukink, H. J., and J. Kroneman. 1963. Een nieuw diagnostisch hulpmiddel bij het onderzoek van het rund op de aanwezigheid van een gedilateerde en/of gedisloceerde lebmaag; het zgn. "Steelband-effect". Tijdsch. Diergeneeskd. 88:282-291.

Centraal Veevoeder Bureau. Voedernormen landbouwhuidieren en voederwaarde veevoeders, verkorte tabel 1998, CVB-reeks nr.24, august 1998 (In Dutch).

Detillieux, J. C., Y. T. Gröhn, S. W. Eicker, and R. L. Quaas. 1997. Effects of left displaced abomasum on test day milk of Holstein cows. J. Dairy Sci. 80:121-126.

Dirksen, G. 1962. Die Erweiterung, Verlagerung und Drehung des Lebmages beim Rind, Berlin and Hamburg, Verlag Paul Parey.

Feng, P., W. H. Hoover, T. K. Miller, and R. Blauwiekel. 1993. Interactions of fiber and nonstructural carbohydrates on lactation and ruminal function. J. Dairy Sci. 76:1324-1333.

Gaal, T., I. M. Reid, R. A. Collins, C. J. Roberts, and B. V. Pike. 1983. Comparison of biochemical and histological methods of estimating fat content of liver of dairy cows. Res. Vet. Sci. 34:245-248.

Geishauser, T. 1995. Abomasal displacement in the bovine-a review on character, occurrence aetiology and pathogenesis. J. Vet. Med. Ser. A. 42:229-251.

Geishauser, T., K. Leslie, T. Duffield, D. Sandals, and V. Edge. 1998. The association between selected metabolic parameters and left abomasal displacement in dairy cows. J. Vet. Med. Ser. A. 45:499-511.

Geishauser, T., K. Leslie, and T. Duffield. 2000. Prevention and prediction of displaced abomasum in dairy cows. Bovine Pract.. 34:51-55.

Gregory, P. C., S. J. Miller, and A. C. Brewer. 1985. The relation between food intake and abomasal emptying and small intestinal transit time in sheep. Br. J. Nutr. 53:373-380. 
Herdt, T. H. 2000. Ruminant adaptation to negative energy balance, influences on the etiology of ketosis and fatty liver. Vet. Clin. North Am. Food Anim. Pract. 16:215-230.

Heuer, C. 2000. Negative energy balance in dairy cows-prediction, consequences, prevention. Ph.D. thesis Utrecht University.

Hill, A. W., I. M. Reid, and R. A. Collins. 1985. Influence of liver fat on experimental Escherichia coli mastitis in periparturient cows. Vet. Rec. 117:549-551.

Holtenius, K., K. Sternbauer, and P. Holtenius. 2000. The effect of the plasma glucose level on the abomasal function in dairy cows. J. Anim. Sci. 78:1930-1935.

Holtenius, P., and K. Holtenius. 1996. New aspects of ketone bodies in energy metabolism in dairy cows: a review. J. Vet. Med. Ser. A. $43: 579-587$.

Kovacs, T. O. G., K. C. K. Lloyd, and J. H. Walsh. 1996. Gastrin partially mediates insulin-induced acid secretion in dogs. Peptides. 17:583-587.

Lam, W. F., A. A. M. Masclee, E. S. M. Muller, and C. B. H. W. Lamers. 1997. Effect of hyperglycemia on gastric acid secretion during gastric phase of digestion. Am. J. Physiol. 272:G1116G1121.

Muylle, E., C. van den Hende, B. Sustronck, and P. Deprez. Biochemical profiles in cows with abomasal displacement estimated by blood and liver parameters. J. Vet. Med. Ser. A. 37:259-263.

Ohtsuka, H., M. Koiwa, A. Hutsugaya, K. Kudo, F. Hoshi, N. Itoh, H. Yokota, H. Okada, and S. Kawamura. 2001. Relationship between serum TNF activity and insulin resistance in dairy cows affected with naturally occurring fatty liver. J. Vet. Med. Sci. 63:10211025 .
Østergaard, S. and Y. T. Gröhn. 2000. Concentrate feeding, drymatter intake, and metabolic disorders in Danish dairy cows. Livestock Production Science. 65:107-118.

Puscas, I., M. Coltau, M. Baican , G. Domuta, and A. Hecht. 2001. Calcium, carbonic anhydrase and gastric acid secretion. Physiol. Res. 50:349-364.

Reid, I. M., and C. J. Roberts. 1982. Fatty liver in dairy cows. In Practice. 4:164-169.

Rukkwamsuk, T. 1999. Negative energy balance in postparturient dairy cows: consequences and adaptations. Ph.D. thesis, Utrecht University.

Shaver, R. D. 1997. Nutritional risk factors in the etiology of left displaced abomasum in dairy cows: a review. J. Dairy Sci. 80:2449-2453.

Trent, A. M. 1990. Surgery of the bovine abomasum. Vet. Clin. North Am. Food Anim. Pract. 6:399-448.

Van der Top, A. M., T. Wensing, M. J. H. Geelen, G. H. Wentink, A. T. van't Klooster, and A. C. Beynen. 1995. Time trends of plasma lipids and hepatic triacylglycerol synthesizing enzymes during postpartum fatty liver development in dairy cows with unlimited access to feeding during the dry period. J. Dairy Sci. 78:22082220.

Van Winden, S. C. L., K. E. Müller, R. Kuiper, and J. P. T. M. Noordhuizen. 2002a. Studies on the $\mathrm{pH}$ value of abomasal contents in dairy cows during the first three weeks after calving. J. Vet. Med. Ser. A. 49:157-160.

Van Winden, S. C. L., C. R. Brattinga, K. E. Müller, J. P. T. M. Noordhuizen, and A. C. Beynen. 2002b. The position of the abomasum in dairy cows during the first six weeks after calving. Vet. Rec. 151:446-449. 